\title{
Wusm

\section{Educação Popular e Resistência: as escolas populares de saúde no Timor-Leste}

\author{
Popular Education and Resistence: the popular health schools in East
}

Timor

\begin{abstract}
* Samuel Penteado Urban
Professor Assistente do Departamento de Educação da Universidade do Estado do Rio Grande do Norte, campus avançado de Patu, Rio Grande do Norte, Brasil.

Doutorando em Educação Científica e Tecnológica pela Universidade Federal de Santa Catarina, Florianópolis, Santa Catarina, Brasil.

samuelurban@uern.br
\end{abstract}

Recebido em 04 de setembro de 2018

Aprovado em 29 de maio de 2019

Publicado em 11 de setembro de 2019

\section{RESUMO}

Timor-Leste é considerada a primeira democracia a se estabelecer como tal no século XXI. Com a invasão indonésia em 1975, houve investimento na construção de escolas - desde a educação infantil até o ensino superior - baseadas em um ensino ideologicamente integracionista e opressor. Em contrapartida, internamente a luta pela restauração da independência contra a invasão indonésia liderada pela Frente Revolucionária de Timor-Leste Independente, iniciou-se um processo de Educação Popular que teve grande influência teórica de Paulo Freire, Mao Tsé-Tung e Amílcar Cabral. Esse processo estava ligado à conscientização política e ao conhecimento cotidiano dos próprios educandos em prol de um ensino contextualizado às necessidades de luta. Dentre as manifestações dessa pedagogia, destacam-se no presente artigo, as escolas populares de saúde, que por meio dos conhecimentos externos (ciência moderna) somados aos saberes locais a Timor, criaram-se centros de saúde, onde eram produzidos medicamentos, oferecidos serviços de saúde à população e realizada a formação de paramédicos para atuarem em meio guerrilha. O objetivo do presente estudo será de realizar apontamentos acerca da educação popular em Timor-Leste, com destaque para as escolas populares de saúde, bem como realizar uma leitura epistemológica. Assim, o presente artigo caracteriza-se como um estudo historiográfico que tem como dados fontes distintas (provenientes da literatura e empíricos oriundos das entrevistas). De forma mais específica, a coleta de dados, deu-se por meio de pesquisa bibliográfica e entrevistas semi-estruturadas com os principais envolvidos na Educação Popular atual de Timor-Leste.

Palavras-chave: Educação Popular; Epistemologias do Sul; Timor-Leste. 


\section{FEM entuabal}

ISSN: 1984-6444 | http://dx.doi.org/10.5902/1984644434613

população podem ser compreendidos como forma de, estrategicamente, manter um maior controle sob a população timorense ${ }^{1}$. Num primeiro momento, não se estabelece com o Timor uma relação de exploração, sendo que, apenas após 1515 se inicia a exploração do sândalo. Nesse período, segundo Silva (2011, p. 04), missionários católicos da Ordem de S. Domingos foram enviados a Timor com o intuito de promover a civilização dos povos menos desenvolvidos. De certa forma, o caso de Timor assemelha-se ao acontecido no Brasil, sendo que o processo de "colonização, foi, sobretudo, uma empreitada comercial. Os nossos colonizadores não tiveram - e dificilmente poderiam ter tido - intenção de criar, na terra "descoberta", uma nova civilização. Interessava-Ihes, em um primeiro momento, a exploração comercial da terra". (FREIRE, 1967, p. 67).

Deste modo, entende-se, segundo Silva (2012), que Portugal não deixou de lado a questão educacional em Timor por falta de interesse, mas sim, proporcionou essa situação de grande analfabetismo no país. Lembrando que as políticas educacionais, como o próprio nome já diz, são atos políticos e, assim, são proporcionados por um ou mais agentes com algum propósito.

Neste caso, uma política educacional que não esteve voltada para a alfabetização da população, permite inferir que havia certa indução no sentido de manter os timorenses submissos de alguma forma. Em outras palavras, pode-se intuir que Portugal teria mantido a situação de analfabetismo no país, pois esta condição de subalternidade dos timorenses Ihe era favorável. Até porque, "não há real ajuda entre classes dominantes e classes dominadas nem entre as 'sociedades imperiais' e as chamadas sociedades dependentes, de fato, dominadas, na compreensão de cujas relações não se pode prescindir da análise de classe" (FREIRE, 1977, p. 16).

Prosseguindo o desenrolar cronológico, Timor proclama sua independência unilateral em 28 de novembro de 1975, através da Frente Revolucionária de TimorLeste Independente - FRETILIN, estabelecendo então, a República Democrática de Timor-Leste $(\mathrm{RDTL})^{2}$. Dias depois, esse processo de independência é interrompido pelos indonésios que invadem o país em 7 de dezembro de 1975, apoiados pelos EUA e Austrália no contexto de Guerra Fria, no sentido de um "despotismo descentralizado" (SANTOS, 2009, 39). Isto é, os Estados Unidos da América (principal agente) realiza 


\section{工 WFM entuabal}

ISSN: 1984-6444 | http://dx.doi.org/10.5902/1984644434613

de forma indireta a invasão em Timor, utilizando-se de representantes regionais geograficamente próximos a Timor-Leste, sendo denominado por Harvey (2004 p. 89) como "hegemons regionais". Estes, representados por Indonésia e Austrália.

Desde então, é quase imediata a proibição do uso da língua portuguesa no ensino timorense, e dá-se início ao uso da língua indonésia ${ }^{3}$. Desta forma, segundo Silva (2011a, p. 10), "todas as posições administrativas, técnicas e profissionais eram cargos ocupados pelos indonésios: $20 \%$ dos professores primários e $90 \%$ dos professores secundários que lecionavam nas escolas não eram timorenses."

Deste modo, o ensino, de modo geral, foi sempre marcado por uma imposição linguística, pela memorização e por um ensino descontextualizado, no qual eram trabalhados conteúdos advindos de Portugal, num primeiro momento, e depois advindos da Indonésia. (ACÁCIO, 2006; GUNN, 2007).

Com a conquista da restauração da independência, Timor-Leste se torna a primeira democracia estabelecida no século XXI e, como resultado histórico de todo esse processo de invasão, constata-se diversos reflexos na sociedade timorense, dentre eles, na educação.

Assim, acrescenta-se que o contexto educacional atual de Timor-Leste é resultado de processos históricos, nos quais se destacam como principais agentes: Portugal, no período das grandes navegações e do imperialismo; Indonésia, no período da Guerra Fria. Neste momento, Estados Unidos da América do Norte e a Austrália possuem relevantes papéis, o primeiro fornecendo armamentos e o segundo com o interesse no petróleo presente no mar do sul de Timor.

Baseando-se em Santos (2009), esse processo histórico de invasões, que resultou nas várias formas de imposição citadas acima (sobretudo pedagógica e linguística) objetivando a exploração territorial timorense, refere-se ao paradigma da apropriação/violência. Isto significa que a "apropriação envolve incorporação, cooptação e assimilação, enquanto a violência implica destruição física, material, cultural e humana" (SANTOS, 2009, p. 29). Assim, essa violência não é apenas física, mas também cultural e humana. Portanto, em relação à violência física, aplica-se a Timor-Leste, quando nos reportamos ao massacre de $1 / 3$ da população leste timorense, sobretudo em função da apropriação do petróleo e das terras de Timor. 


\section{HEM entuabal}

ISSN: 1984-6444 | http://dx.doi.org/10.5902/1984644434613

O presente trabalho objetiva realizar apontamentos históricos e conceituais acerca da educação popular no Timor-Leste no contexto da resistência contra os invasores indonésios, com destaque para as escolas populares de saúde, realizando um pequeno paralelo com as epistemologias do sul. De forma mais detalhada, na primeira seção, buscou realizar alguns apontamentos acerca da educação popular e as principais influências externas e internas ao Timor-Leste; em seguida, buscou destacar as escolas populares de saúde, bem como estabelecer um pequeno paralelo com as Epistemologias do Sul.

Cabe destacar que as duas seções do texto compõem um estudo historiográfico que tem como dados fontes distintas - dados provenientes da literatura e dados empíricos oriundos das entrevistas ${ }^{4}$.

Os resultados obtidos, somente foram possíveis por meio da experiência de 18 meses realizada junto ao Programa de Qualificação Docente e Ensino de Língua Portuguesa no Timor-Leste (PQLP) ${ }^{5}$, que tem como foco principal a formação inicial e continuada de professores, atuando "como país cooperante em ações de formação de professores - com a integração entre ensino, pesquisa e extensão no território timorense." (PEREIRA; NETO; CASSIANI, 2015, p. 205).

Quanto aos procedimentos metodológicos desta pesquisa, ela insere-se em seu aspecto geral, no que se denomina comumente como pesquisa qualitativa. Assim, realizou-se levantamento e aprofundamento teórico em temas como história da educação em Timor-Leste, Educação Popular em Timor-Leste e Epistemologias do Sul. Em função do pouco material bibliográfico, fez-se também necessária a realização de entrevistas semi-estruturadas na língua Tétum (língua oficial de TimorLeste juntamente com o Português) com o Professor Dr. Antero Benedito da Silva ${ }^{6}$ e com o Sr. Alberto ${ }^{7}$, atual presidente do principal movimento social do campo de TimorLeste denominado União dos Agricultores de Ermera (UNAER).

\section{Apontamentos históricos acerca da Educação Popular}

A partir de entrevistas realizadas e da bibliografia analisada, pôde-se constatar que as lutas em Timor-Leste, desde o período da colonização portuguesa até os dias 


\section{HSW efitrabac}

ISSN: 1984-6444 | http://dx.doi.org/10.5902/1984644434613

atuais, basicamente se concentram nas lutas pelo direito à terra, pela alfabetização associada a um processo de conscientização política ${ }^{8}$ e pela conquista/restauração da independência.

Em cada período histórico ou, como destaca Freire (1997), em cada unidade epocal $^{9}$, uma luta se sobrepõe à outra, em função das necessidades prioritárias do momento. Desta forma, no período que antecede 1975, a luta primordial dos timorenses foi pela conquista da independência. Tal luta englobava, ainda, as lutas pelo acesso à terra e pela alfabetização, já que nesse período, em especial no distrito de Ermera, a Sociedade Agrícola Pátria e Trabalho (SAPT) ${ }^{10}$ utilizava as terras para cultivo do café, fazendo com que os timorenses trabalhassem num regime de quase escravidão no lugar em que outrora foram donos.

No período indonésio, a luta primordial era para que a República Democrática de Timor-Leste (RDTL) restaurasse a independência. Assim, tanto as lutas pela terra como as contra o analfabetismo estiveram internalizadas com foco na conquista da independência. Destaca-se o papel da empresa P. T. Demok Hernandes International como responsável pelo monopólio da terra durante o regime indonésio, pois explorava a situação economicamente através da produção cafeeira, fazendo dos timorenses seus funcionários nos mesmos moldes da SAPT. Com relação à Educação, diferentemente do período de colonização portuguesa, houve uma extensa política educacional, porém, esta encontrava-se ligada a um processo em que se priorizava uma educação "bancária" (FREIRE, 1997) e integracionista11.

Com relação à unidade epocal na qual o Timor estava inserido, associado a um contexto de lutas pela libertação nacional, o professor Antero afirma que a "Educação Popular em Timor tem várias dimensões, vários teóricos, vários fundamentos de teoria" (SILVA, 2016, p. 165). Essas dimensões da Educação Popular permeiam desde a campanha de alfabetização realizada pela FRETILIN, até a produção de medicamentos ligada à formação de pessoas para lutarem na guerrilha como paramédicos (SILVA, 2016, p. 166). De forma geral, "O termo 'educação popular' descreve o programa de educação alternativo da FRETILIN realizado entre 1974 e 1999." (SILVA, 2011, p. 3, tradução do autor). 


\section{HEM eltibará}

ISSN: 1984-6444 | http://dx.doi.org/10.5902/1984644434613

Segundo Silva (2014, p. 40, tradução do autor), tais influências estão permeadas pela "teoria de classe de Karl Marx: camponês contra latifundiário [...]; classe burguesa e classe do proletariado no sistema capitalista; e colonizado contra colonialistas no sistema colonial." Especificamente foram utilizados alguns pensadores marxistas no desenvolvimento do pensamento timorense em relação à Educação, sendo Paulo Freire, Amílcar Cabral e Mao Tsé-Tung os principais (SILVA, 2016, p. 166).

Assim, pode-se dizer que se trabalhava em frentes distintas neste processo de Educação Popular. Em um primeiro momento, houve o início da campanha de alfabetização que englobava pressupostos teóricos ligados a um ensino de conscientização política. Em um segundo momento, houve a própria escola de formação política, que partia dos mesmos pressupostos, mas tinha como público-alvo lideranças da FRETILIN, militares e alguns jovens já alfabetizados, incluindo aqui, as escolas populares de saúde.

A influência de Paulo Freire foi aquilo que deu grande suporte à campanha de alfabetização realizada pela FRETILIN, englobando um trabalho de base que se utilizava de práticas culturais do povo, juntamente com o uso de temas geradores ${ }^{12}$, visando a uma educação direcionada para a emancipação que, no caso de Timor, se concretizaria através da libertação nacional contra Portugal, em um primeiro momento e, posteriormente, contra o regime indonésio. Dessa forma, segundo o Programa Político da FRETILIN de 1974, "para constituirmos um Timor verdadeiramente livre e independente, é necessário que todos, homens, mulheres, velhos, jovens, crianças, todos saibam ler e escrever." (FRETILIN, 1974, p. 19).

A influência de Mao Tsé-Tung se deu com o trabalho de base realizado pela FRETILIN com apoio da União dos Estudantes de Timores (UNETIM). Esse trabalho ocorreu nas bases de apoio que lutavam pela independência e, logo depois, na resistência contra a invasão indonésia. Nessas escolas, localizadas próximas às aldeias, encontravam-se integrantes das Forças Armadas de Libertação Nacional de Timor-Leste (FALINTIL) e a população civil, em geral, incluindo os trabalhadores e trabalhadoras da agricultura ${ }^{13}$ e suas famílias. 


\section{工证 Autlathat}

ISSN: 1984-6444 | http://dx.doi.org/10.5902/1984644434613

Nesse trabalho de base, houve também a influência de Amilcar Cabral através do PAIGC, aprendido quando em Portugal, os estudantes da Casa dos Timores tiveram contato com integrantes desse partido político africano (SILVA, 2014, p. $40)^{14}$ e com a obra de Cabral intitulada Pedagogy o fthe Liberation Struggle. Dessa forma, as bases de apoio em Timor foram influenciadas por Mao Tse-Tung e Amilcar Cabral. Assim, considerando a Educação como uma arma política (SILVA, 2011), a influência de Cabral veio no sentido de

[...] uma educação mais política, [...] [sendo] a dos esclarecimentos, mistura de uma propaganda política ${ }^{15}$ e literacia política sobre conceitos e teorias principais, por exemplo, as teorias revolucionárias marxistas, Teoria de Mao Tsé-Tung e Amilcar Cabral em África. (SILVA, 2016, p. 166)

É relevante ressaltar que, dentre as práticas realizadas pelo PAIGC ${ }^{16}$, almejou-se um desenvolvimento da agricultura, da saúde e da luta contra o analfabetismo. (SILVA, 2011, p. 84, tradução do autor). De forma semelhante, o mesmo ocorreu em Timor, com suas peculiaridades inerentes à educação timorense ligada à libertação nacional, denominada como Pedagogia Maubere.

Nesse sentido, em Cartas à Guiné-Bissau, Freire (1977) destaca que não se deve pensar

[...] a alfabetização de adultos em si mesma, reduzindo-a a um puro aprendizado mecânico da leitura e da escrita, mas como um ato político, diretamente associado à produção, à saúde, ao sistema regular de ensino, ao projeto global de sociedade a ser concretizado, ver e ouvir, indagar e discutir, partindo embora do Comissariado de Educação, teriam de prolongar-se a outros comissariados, ao Partido, incluindo as suas organizações de massas (FREIRE, 1977, p. 20)

Nessa educação, baseada na prática, os estudantes foram sujeitos primordiais para que esse processo de Educação Popular pudesse acontecer. Assim, destacase uma educação política intimamente ligada com a formação de uma consciência política "para além de um limite mínimo que é a consciência das suas necessidades" (CABRAL, s/d, p. 84). Desse modo, a Educação Popular timorense, embasada nos pressupostos teóricos destacados acima, resultou de uma série de influências teóricas distintas com o intuito de criar uma educação contextualizada a Timor, sendo denominada como Pedagogia Maubere (SILVA, 2011; 2012; 2014). 


\section{HEM Eltibará}

ISSN: 1984-6444 | http://dx.doi.org/10.5902/1984644434613

De forma geral, percebe-se que, em todo esse contexto histórico de educação popular, destaca-se a dialeticidade existente entre pensamento abissal e pensamento pós-abissal. O primeiro refere-se ao pensamento advindo de uma cultura ocidental que se coloca como sendo a superioridade da sapiência, isto é, o universo existente, os civilizados, que foram impostos pelos invasores. Já o segundo, diz respeito a uma "ecologia de saberes", buscando uma superação da hierarquia de saberes, sendo que determinado conhecimento pode ser válido para determinada sociedade, mas não para outra.

O pensamento abissal pode ser entendido no contexto colonial timorense, por meio da apropriação/violência. As sociedades metropolitanas - Portugal, Indonésia, Austrália e E.U.A. - utilizaram-se dessa dicotomia apropriação/violência, para a exploração econômica do território de Timor, utilizando-se da força, impondo suas línguas, culturas e pedagogias, com o objetivo de apropriação do petróleo, da produção de café, do turismo, além da própria anexação espaço-territorial.

Em contrapartida, internamente a uma luta de resistência contra os invasores indonésios, em especial de 1975 a 1999, houve a formação de escolas de educação popular, que podem ser entendidas por meio de um pensamento pós-abissal, utilizando-se do que Santos (2009) denomina como "ecologia de saberes". Em outras palavras, o pós-abissal é tido como o contra hegemônico ${ }^{17}$, o que não está incluso no pensamento ocidental, e que visa à horizontalidade entre os saberes (ecologia de saberes). Considera-se como válido, àqueles conhecimentos/saberes que suprem as necessidades de determinada sociedade para determinada situação, como foi o caso da utilização da ciência moderna em consonância com alguns dos saberes tradicionais indígenas sobre plantas locais para a obtenção de medicamentos e sequente formação de paramédicos para auxiliarem na guerrilha. Nas palavras de Santos (2009, p. 49), essas práticas advêm da "riqueza dos conhecimentos que conseguiram preservar modos de vida, universos simbólicos e informações vitais para a sobrevivência em ambientes hostis." 


\section{Eltínậão}

ISSN: 1984-6444 | http://dx.doi.org/10.5902/1984644434613

\section{As escolas populares de saúde}

Além das influências externas (Paulo Freire, Amilcar Cabral e Mao Tsé-Tung), fazem parte da história da Educação Popular de Timor-Leste, algumas figuras internas ao país. Dentre esses, destacam-se os principais responsáveis pelas escolas populares de saúde: Manuel Gama (Dr. Lekdoe) e João Varudo (Dr. Maubere).

Nesse sentido, como ponto de partida, fez-se necessário realizar um pequeno enquadramento espacial do país objeto desta pesquisa. Este se localiza no sudeste asiático, compreendendo uma pequena área de aproximadamente $15000 \mathrm{~km}^{2}$ (MAPA $01)$.

Figura 1 - Mapa Político de Timor-Leste

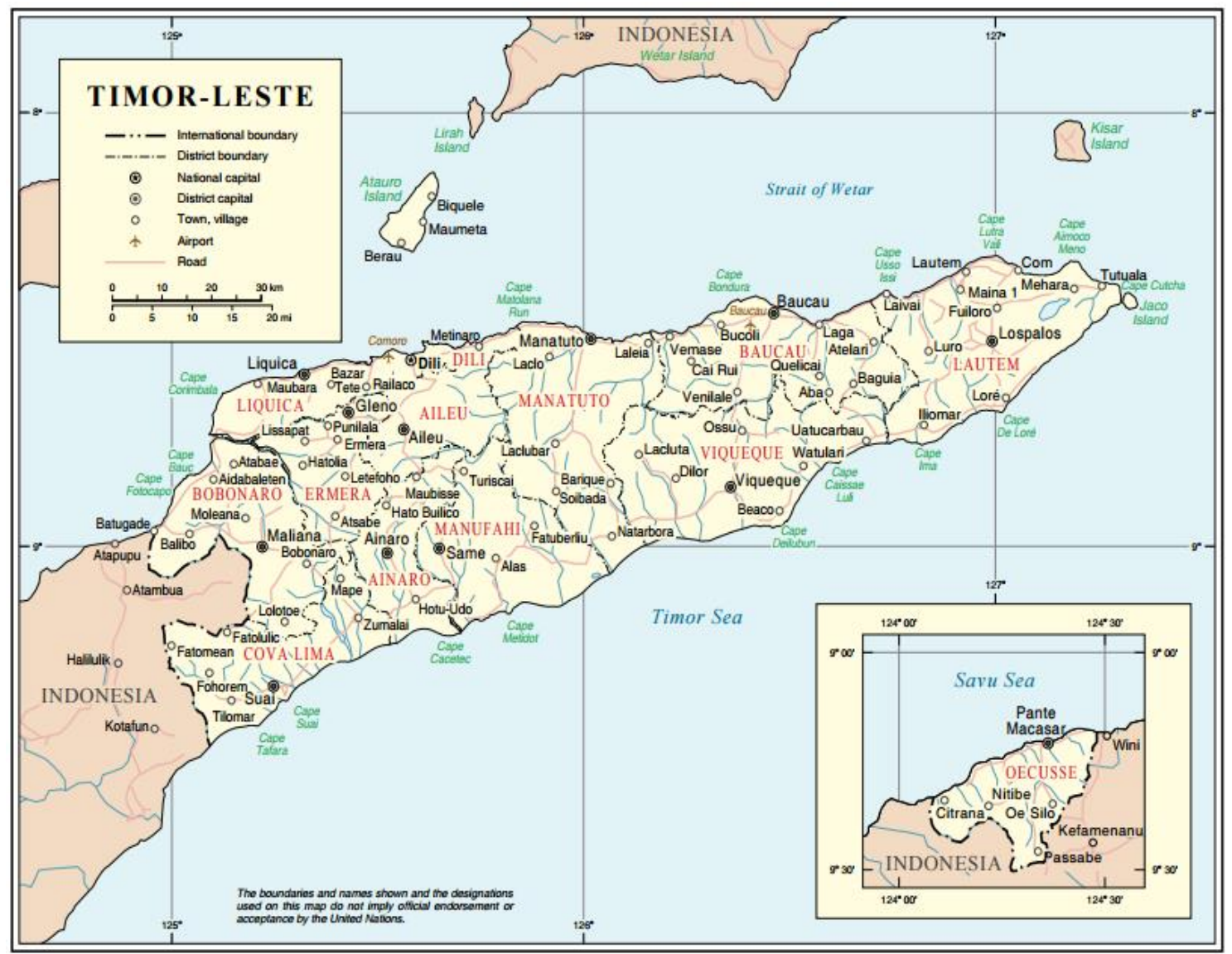

Fonte: UN Cartographic (2011) 


\section{HEM entuabal}

ISSN: 1984-6444 | http://dx.doi.org/10.5902/1984644434613

Uma das principais bases da resistência em Timor encontrava-se no monte Matebian e, em consequência da guerra e dos problemas de saúde acumulados durante anos, o governo da RDTL construiu três centros de saúde e educação em Baguia (subdistrito de Baucau próximo ao Matebian): Centro de Saúde em Samalari, onde foram produzidos comprimidos e fornecidos serviços de saúde; Centro de Saúde na aldeia Bibela, com produção de comprimidos e realização de serviços de saúde e, um terceiro e talvez o mais importante Centro de Produção de Medicamentos em Kaisae-Hoo. Este último foi criado por Manuel Gama, que construiu depois outro ramo desse centro em Uato-Lari, em meados de 1977. (SILVA, 2011, p. 215-216). Nesses três centros de saúde eram realizadas pesquisas médicas e produção de medicamentos. Eis o que registra Silva (2011):

[...] com base em suas próprias experiências, [...] para experimentar e ter sucesso. Eles eram, portanto, centros de educação popular e de aprendizagem, fazendo uma contribuição única para a luta de libertação nacional contra a ocupação indonésia, e além" (SILVA, 2011, p. 216, tradução do autor).

Essa foi, então, uma das diversas dimensões da Educação Popular no TimorLeste, que, nas palavras de Freire (1977, p. 30) é uma educação baseada na prática, isto é, fundada "sempre na prática de pensar a prática, com que a prática se aperfeiçoa". Em outras palavras, foi na aprendizagem do fazer que se realizou esse processo.

Essa prática, portanto, seria a forma de validação desse conhecimento, como um dos meios para conquista da restauração da independência. Nesse sentido, o pensamento pós-abissal a que se refere o presente trabalho, traz consigo 0 "pragmatismo epistemológico", que tem sua origem no movimento pragmático de John Dewey, Sanders Peirce e William James, mas que apresenta inovação em relação ao pragmatimo clássico, sobretudo por questionar o status quo. (NUNES, 2009).

Esse pragmatismo tem como caráter de validação do conhecimento, testes que, por meio de suas consequências, "permitam resolver o problema específico que suscitou essas operações" (DEWEY, 1991 apud NUNES, 2009, p. 225). Em outras palavras, o pragmático "privilegia as consequências em lugar das causas" 


\section{HEM entuabal}

ISSN: 1984-6444 | http://dx.doi.org/10.5902/1984644434613

(NUNES, 2009, p. 226). Porém, o principal ponto da inovação pragmática presente nas epistemologias do sul, é que o critério é realizado pelos oprimidos, e não mais por um mediador advindo de fora do contexto, mesmo que este último tenha as melhores das intenções. Desta forma, para se atingir a emancipação faz-se necessário, que os sujeitos que sofrem, realizem por meio de suas práticas, a construção da restauração da independência, construindo na denúncia um anúncio a ser feito e desvelando as verdadeiras contradições do capitalismo, materializado pelas invasões sofridas. (FREIRE, 1997; SILVA, 2004; DUSSEL, 1977).

Nesse sentido, o pragmatismo contido nas epistemologias do sul e que foi utilizado nas escolas populares de saúde aqui apresentadas, caracteriza-se por uma

[...] reconstrução radical de um pragmatismo que procura emancipar-se dos últimos resquícios do projecto da epistemologia convencional nomeadamente soberania epistémica -, simetrizando os saberes existentes no mundo e, ao mesmo tempo, ancorando a reflexão sobre eles no seu carácter situado e nas condições locais e situadas da validade de cada um deles, aferidas a partir das suas consequências (NUNES, 2009, p. 226)

Partindo dessa perspectiva de referência à epistemologia e ao pragmatismo e a sua associação às experiências dos oprimidos no contexto em que vivem (NUNES, 2009), é que se pode compreender a validade da união existente entre saberes locais sobre plantas medicinais em consonância com saberes advindos de uma ciência moderna. Nas palavras de Nunes (2009, p. 219), "as condições de produção e validação do conhecimento só poderiam ser determinadas de maneira adequada a partir de um conhecimento das próprias práticas de produção e validação de conhecimentos." Avaliação esta, que só pôde ser realizada pelos sujeitos envolvidos naquele contexto de resistência e que viram a necessidade da criação de escolas populares de saúde, isto é, "justificado pelo facto de as experiências de vida dos oprimidos thes serem inteligíveis por via de uma epistemologia das consequências." (SANTOS, 2009, p. 50-51).

Nesses moldes, destacam-se os papéis do Dr. Maubere e do Dr. Lekdoe que no depoimento de Silva (2016) apresentam 


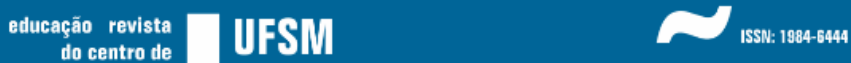

ISSN: 1984-6444 | http://dx.doi.org/10.5902/1984644434613

[...] outro tipo de Educação Popular [que] foi através da introdução de plantas indígenas para serem medicinas, FRETILIN construiu escolas populares de saúde nas bases de apoio, havendo destaque para dois nomes famosos: o Dr. Maubere, foi iliterado ${ }^{18}$, mas ele conhecia bem plantas indígenas então promoveu um centro de educação no centro norte em Remexio e conseguiu educar quase 200 paramédicos para trabalhar em todo o campo das bases de apoio. Em outras partes do país, Manuel Gama (Dr. Lekdoe) foi analfabeto também. Ele foi preso em Angola em 1959 e depois voltou para Timor mais tarde em 1960 e, depois quando Indonésia invadiu esteve em Timor também. Em Angola anteriormente, ele trabalhou com um Doutor Português que fez pesquisa sobre plantas indígenas em Angola, ele aprendeu sem escrever, só vendo e praticando. Quando indonésia invadiu ele surgiu como enfermeiro e, estabeleceu um centro de produção de medicinas e conseguiu trabalhar até o final das bases de apoio em 1978. Ele teve muitos alunos paramédicos que trabalharam com ele. $\mathrm{O}$ centro funcionava em Baguia, centralizado em Baguia, mas em outras bases de apoio havia também práticas de produção de medicinas com plantas indígenas. Isso pra mim foi científico e Político. (SILVA, 2016, p. 166)

Essa luta, que se utilizou da educação como um meio para a conquista da restauração da independência juntamente com a produção de medicamentos, vai de encontro ao destacado por Santos (2009, p. 41) de que "[...] não existe justiça social global sem justiça cognitiva global”. Pois, ao mesmo tempo em que se produziam medicamentos, também se buscava a formação de pessoas para trabalharem como paramédicos no contexto da guerrilha. Isso significa que a tarefa crítica que se avizinhava naquele contexto, não ficou limitada à geração de alternativas, mas "[...] de facto, um pensamento alternativo de alternativas" (SANTOS, 2009, p. 41).

Pensamento este, que buscou dar "credibilidade para os conhecimentos não científicos" (SANTOS, 2009, p. 48), mas sem desconsiderar o próprio conhecimento científico moderno, promovendo a "interação e interdependência entre os saberes científicos e outros saberes" (SANTOS, 2009, p. 48). Até porque, além do próprio uso da ciência moderna (medicina advinda de Portugal), houve "práticas científicas alternativas" (SANTOS, 2009, p. 48), afirmado por Silva (2016) no trecho da entrevista acima como práticas científicas e políticas.

Cabe destacar que, Manuel Gama residiu em Portugal e lá aprendeu acerca das práticas ligadas à saúde e também pressupostos teóricos de Amílcar Cabral. Tem-se, então, essa experiência teórica traduzida em uma educação de caráter político e científico, direcionada à libertação nacional de Timor-Leste, tanto em seu aspecto formativo, quanto no que se refere às necessidades básicas da população 


\section{- ussm,

ISSN: 1984-6444 | http://dx.doi.org/10.5902/1984644434613

com relação à mortalidade. Nesse sentido, tem-se o trabalho sistematizador do conhecimento que,

[...] proporcionaria o surgimento de verdadeiros centros de estudos que, girando embora em torno de um tema central - agricultura, saúde, por exemplo - desenvolveriam análises globais dos mesmos. Centros que se iriam convertendo a pouco e pouco, em função mesma de trabalho sistematizador do conhecimento, em permanente processo de aprofundamento (FREIRE, 1977, p. 30).

Assim, Silva (2011) define este processo como second cultural army, pelo qual

[...] dois analfabetos, Manuel Gama 'Lekdoe' e João Varudo 'Doctor Maubere', tornaram-se figuras proeminentes, usando sua "inteligência natural" e conhecimento local para a produção de medicamentos, o que demonstra que o conhecimento indígena e fitoterapia são poderosos meios de revolução no sector da saúde (SILVA, 2011, p. 228, tradução do autor).

Em síntese, é possível afirmar, que as três influências externas ao país asiático, tiveram grande papel nas escolas populares de saúde (TABELA 01): Paulo Freire em relação a uso de práticas culturais do povo, materializados nos conhecimentos locais; Mao Tsé-Tung referente à educação realizada diretamente nas bases da sociedade timorense, sendo os civis integrantes das escolas; e por último, a influência de Amilcar Cabral acerca das escolas de saúde realizadas em contexto semelhante ao de Timor, no continente africano.

Como mediadores desse processo, destacam-se os papeis de figuras da Pedagogia Maubere, sendo eles o Dr. Lekdoe e o Dr. Maubere.

Quadro 1 - Síntese das influências nas escolas populares de saúde em Timor-Leste

\begin{tabular}{|c|c|c|}
\hline INFLUÊNCIAS EXTERNAS & $\begin{array}{c}\text { PEDAGOGIA } \\
\text { MAUBERE }\end{array}$ & CARACTERISTICAS \\
\hline \multirow{2}{*}{$\begin{array}{c}\text { Paulo Freire } \\
\text { Amilcar Cabral }\end{array}$} & $\begin{array}{c}\text { Educação e Saúde } \\
\text { (Centros de saúde - } \\
\text { PAIGC); }\end{array}$ \\
\cline { 3 - 3 } Mao Tsé-Tung & $\begin{array}{c}\text { Dr. Lekdoe } \\
\text { Dr. Maubere }\end{array}$ & $\begin{array}{c}\text { Educação baseada na nas bases da } \\
\text { prática; } \\
\text { sociedade timorense }\end{array}$ \\
\cline { 3 - 3 } & & $\begin{array}{c}\text { Uso das práticas culturais } \\
\text { do povo. }\end{array}$ \\
\hline
\end{tabular}

Fonte: Elaboração própria. 


\section{HEM entuabal}

ISSN: 1984-6444 | http://dx.doi.org/10.5902/1984644434613

Pensando esse processo com as lentes das epistemologias do sul, observase aqui, a presença do pensamento pós-abissal - que parte das experiências dos oprimidos -, ou seja, do "pragmatismo epistemológico". Nesse sentido, esse pensamento pós-abissal busca uma contraposição à crença na ciência moderna como único conhecimento válido e, consequentemente, é tido como uma forma de resistência aos desígnios da dominação colonial e imperial (SANTOS, 2009, p. 47). Nisso, esse pensamento pós-abissal, mais especificamente a ecologia de saberes, busca valorizar "outros conhecimentos não científicos e não-ocidentais [que] prevalecem nas práticas quotidianas das populações" (SANTOS, 2009, p. 47).

Ainda com relação à ecologia de saberes, Santos (2009) afirma que,

[...] nenhuma forma singular de conhecimento pode responder por todas as intervenções possíveis no mundo, todas elas são, de diferentes maneiras, incompletas. [...] Não há conhecimento que não seja conhecido por alguém para alguns objetivos. Todos os conhecimentos sustentam práticas e constituem sujeitos (SANTOS, 2009, p. 49)

Cabe destacar que uma das "premissas da ecologia de saberes é que todos os conhecimentos têm limites internos e limites externos. Os internos dizem respeito aos limites das intervenções no real que permitem" (SANTOS, 2009, p. 48). Isto é, a formação de paramédicos e a produção de medicamentos - voltados àquele momento específico de resistência, naquelas localidades onde se instalaram as escolas populares em que eram utilizados de conhecimentos específicos de plantas locais em adição aos conhecimentos advindos da ciência moderna (medicina) - não se aplicam a outros contextos (espaciais, temporais e situacionais), pois a validação daqueles conhecimentos foi realizada por uma parcela do povo timorense em específico, para aquele contexto.

Com relação aos limites externos, estes "decorrem do reconhecimento de intervenções alternativas tornadas possíveis por outras formas de conhecimento." (SANTOS, 2009, p. 50). Ou seja, além do uso dos conhecimentos locais, os timorenses utilizaram dos conhecimentos advindos da medicina (ciência moderna), havendo uma mescla de conhecimentos, que foram válidos para àquele contexto, em que as práticas de conhecimento possibilitaram certas intervenções no mundo real. 


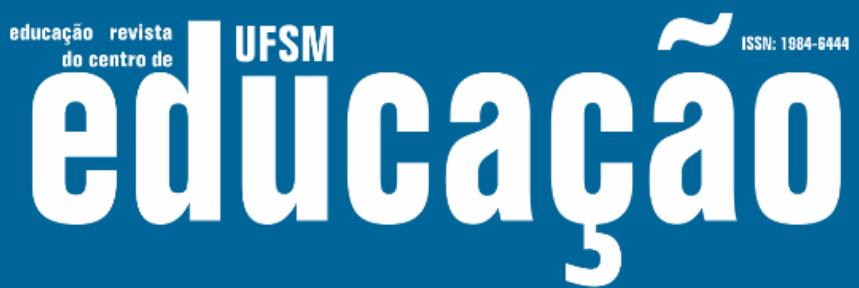

ISSN: 1984-6444 | http://dx.doi.org/10.5902/1984644434613

\section{Considerações Finais}

De forma sintética, o presente artigo visa contribuir com o desenvolvimento da educação no Timor-Leste, sobretudo no que se refere à educação popular como uma alternativa a uma educação opressora que se deu no passado, mas que ainda se manifesta ligada a lógica do neoliberalismo.

Por meio de imposições realizadas através de invasões a República Democrática de Timor-Leste, houve a difusão de um pensamento abissal, por meio da apropriação/violência, representado pela língua, cultura e educação advindas do opressor. Em contrapartida, partindo de um pensamento pós-abissal, ou seja, da "existência de uma pluralidade de formas de conhecimento" (SANTOS, 2009, p. 45), buscou-se por meio de práticas culturais do povo, uma educação diretamente na base da sociedade timorense, com a criação de escolas populares de saúde, que como conhecimento válido para àquele contexto, mesclaram saberes locais acerca de plantas medicinais aos saberes advindos da ciência moderna, representadas pela medicina ocidental (ecologia de saberes).

Assim, entende-se aqui, que as escolas de educação popular de Timor-Leste fazem parte de um movimento contra-hegemônico, ligado a uma resistência epistemológica e, que, foram essenciais para a conquista da restauração da independência em 2002.

Atualmente, a Educação Popular no Timor-Leste, que teve origem em 1974, está relacionada a outro contexto de lutas. Isto é, após o processo de restauração da independência em 2002, a luta pela reforma agrária e por uma economia mais justa e alternativa, se tornou pauta da sociedade civil no Timor-Leste, com destaque para o movimento social do campo União dos Agricultores de Ermera (UNAER), que em parceria com o Instituto de Paz e Conflito da Universidade Nacional de TimorLorosa'e (UNTL) idealizou e pôs em prática o Instituto de Economia Fulidaidai-Slulu.

Por fim, partindo de uma perspectiva crítica de educação, isto é, de que há uma relação dialética entre educação e sociedade, faz-se necessário ter em mente que não há justiça social, sem justiça cognitiva global (SANTOS, 2009). 


\section{त Wsm entuahá}

ISSN: 1984-6444 | http://dx.doi.org/10.5902/1984644434613

\section{Referências}

ACÁCIO, Manuel. A última bala é a minha vitória: A história secreta da resistência timorense. Dafundo: Oficina do livro, 2006.

ALBERTO (2015). Apêndice 02. In: URBAN, Samuel Penteado. A formação da Escola de Educação Popular Fulidaidai-Slulu em Timor-Leste: uma história de resistência. 2016. 204 f. Dissertação (Mestrado em Educação) - Universidade Federal de São Carlos, 2016.

CABRAL, Amilcar. Amilcar Cabral. Cabo Verde, s/d. 114 p. Disponível em http://www.amilcarcabral.org/livro.pdf. Acesso em outubro 2015.

DUSSEL, Enrique D. Filosofia da Libertação. São Paulo: Edições Loyola, 1977.

FREIRE, Paulo. Ação Cultural para a liberdade e outros escritos. 13. ed. Rio de Janeiro: Paz e Terra, 2010.

FREIRE, Paulo. Cartas à Guiné-Bissau: registros de uma experiência em processo. 2. ed., Rio de Janeiro, Paz e Terra, 1977.

FREIRE, Paulo. Educação como prática da liberdade. Rio de Janeiro: Paz e Terra, 1967.

FREIRE, Paulo. Extensão ou Comunicação? 7. ed. Rio de Janeiro: Paz e Terra, 1985.

FREIRE, Paulo. Pedagogia do Oprimido. 27. ed. Rio de Janeiro: Paz e Terra, 1997.

FRETILIN-Frente Revolucionária de Timor-Leste Independente. FRETILIN/Manual e

Programa Políticos. Lisboa, CasaComum.org, 1974. Disponível em http://hdl.handle.net/11002/fms_dc_130467. Acesso em 02 outubro 2015.

GUNN, Geoffrey C. A ocupação indonésia em Timor-Leste: Lições e legados para a construção do Estado da nova nação. In: SILVA, Kelly Cristiane da; SIMIÃO, Daniel Schroeter. Timor-Leste por trás do palco: Cooperação internacional e a dialética da formação do Estado. Belo Horizonte, Editora UFMG, 2007. p. 40-62.

HARVEY, David. O novo imperialismo. São Paulo: Edições Loyola, 2004.

NUNES, João Arriscado. O resgate da Epistemologia. In: SANTOS, Boaventura de Sousa; MENESES, Maria Paula. Epistemologias do Sul. Coimbra: CES, 2009.

PEREIRA, Patrícia Barbosa; NETO, Francisco Fernandes Soares; CASSIANI, Suzani. Formação científica de professores em Timor-Leste: análise de uma intervenção. In: GUEDES, Maria Denise, et. al. Professores sem fronteiras: pesquisas e práticas pedagógicas em Timor-Leste. Florianópolis, NUP/UFSC, 2015. 


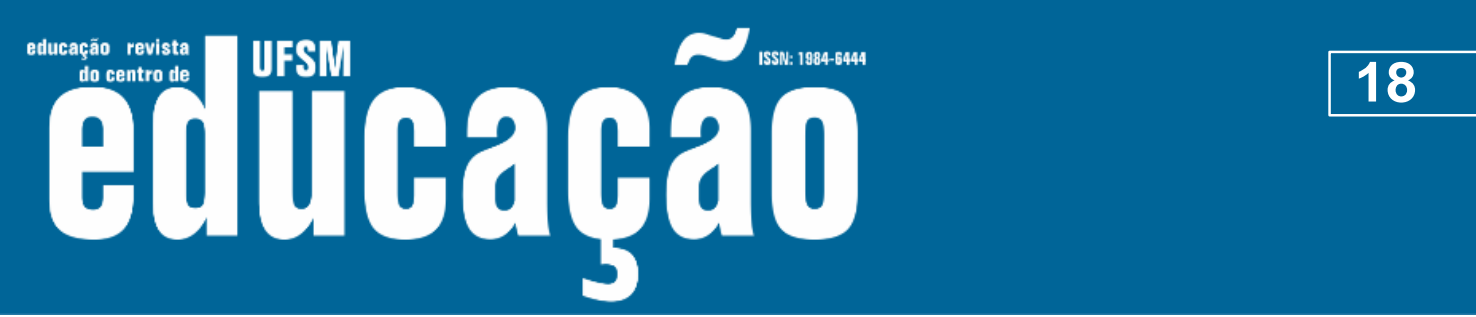

ISSN: 1984-6444 | http://dx.doi.org/10.5902/1984644434613

RAMOS, André Gonçalves et.al. Práticas didáticas de professores brasileiros de língua portuguesa em Timor-Leste. In: GUEDES, Maria Denise, et. al. Professores sem fronteiras: pesquisas e práticas pedagógicas em Timor-Leste. Florianópolis, NUP/UFSC, 2015.

SANTOS, Boaventura de Sousa. Para além do Pensamento Abissal: das linhas globais a uma ecologia de saberes. In: SANTOS, Boaventura de Sousa; MENESES, Maria Paula. Epistemologias do Sul. Coimbra: CES, 2009.

SILVA, Antero Benedito da. Apêndice 01. In: URBAN, Samuel Penteado. A formação da Escola de Educação Popular Fulidaidai-Slulu em Timor-Leste: uma história de resistência. 2016. 204 f. Dissertação (Mestrado em Educação) - Universidade Federal de São Carlos, 2016.

SILVA, Antero Benedito da. Fulidaidai: Dalan Kultural ba Dezenvolvementu Kooperativu. Klaak-semanal, 2008. Disponível em http://klaaksemanal.blogspot.com.br/2008/03/fulidaidai-dalan-kultural-ba.html. Acesso em jul. 2014.

SILVA, Antero Benedito da. FRETILIN Popular Education 1973-1978 and its relevanceto Timor-Leste today. 2011. 327 f. Tese (Doutorado em Filosofia) Universityof New England, 2011.

SILVA, Antero Benedito da. LiteracyModelofthe Maubere Pedagogy. Comunicação apresentada no Grupo de Estudos Brasil-Timor (Peace andConflictStudiesInstitute), 2012.

SILVA, Antero Benedito da. Foinsa'e e Maubere: Historia Luta baUkun-Rasik-nahusi UNETIM ba DSMPPTL. Aileu: IEDKS, 2014.

SILVA, Antero Benedito da. Apêndice 01. In: URBAN, Samuel Penteado. A formação da Escola de Educação Popular Fulidaidai-Slulu em Timor-Leste: uma história de resistência. 2016. 204 f. Dissertação (Mestrado em Educação) - Universidade Federal de São Carlos, 2016.

SILVA, Antonio Fernando Gouvêa da. A construção do currículo na perspectiva popular crítica: das falas significativas às práticas contextualizadas. 2004. 405 f. Tese (Doutorado em Educação) - Pontifícia Universidade Católica de São Paulo, 2004.

UNITED NATIONS - MDG. Joint Program: Promoting Sustainable Food and Nutrition Security in Timor-Leste.Final Report. Díli, 2011. Disponível em: http://www.mdgfund.org/sites/default/files/Signed_JP_Timor_Leste_Children_Sept09. pdf. Acesso em: jan. 2016. 


\title{
-

ISSN: 1984-6444 | http://dx.doi.org/10.5902/1984644434613

\section{Correspondência}

Samuel Penteado Urban - Universidade do Estado do Rio Grande do Norte - Av. Lauro Maia, s/n - CEP 59770-000, Centro, Patu, Rio Grande do Norte, Brasil.

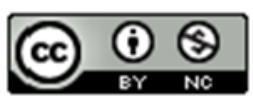

This work is licensed under a Creative Commons Attribution-NonCommercial 4.0 International (CC BY-NC 4.0)

\section{Notas}

\begin{abstract}
${ }^{1}$ Isso não quer dizer que os timorenses não questionassem este estado de coisas, pelo contrário. A independência de Timor em 1975 e depois a restauração da mesma em 2002, foi fruto de uma organização e resultado de processos educativos internos ligados a FRETILIN (Frente Revolucionária de Timor-Leste Independente).
\end{abstract}

${ }^{2}$ Esta se manteve mesmo com a invasão indonésia.

${ }^{3}$ Destaca-se que, um importante ator da difusão da Língua Portuguesa no Timor-Leste, foi a Igreja Católica. Esta que respondia ao Vaticano e não a Jacarta. A ilustração desse contexto, pode ser visto no episódio acorrido em 1983, em pleno regime indonésio, quando a Escola Portuguesa localizada em Díli, foi reaberta oferecendo cursos na Língua Portuguesa, fora do currículo nacional proposto pelos indonésios. (GUNN, 2007, p. 51)

${ }^{4}$ Realizadas na língua Tétum - oficial em Timor-Leste ao lado da língua portuguesa.

${ }^{5}$ Cooperação educacional brasileira no Timor-Leste.

${ }^{6}$ Foi liderança da juventude estudantil durante a resistência timorense contra os invasores indonésios e atualmente é Professor da Universidade Nacional de Timor Lorosa'e (UNTL).

${ }^{7}$ Foi guerrilheiro durante a resistência timorense contra os invasores indonésios.

8 "O termo "conscientização" derivada de Paulo Freire, foi usado por FRETILIN para descrever seu "trabalho de base e campanha de alfabetização.” (SILVA, 2011, p. 8, tradução do autor).

${ }^{9}$ Freire (1997) destaca unidade epocal e subunidade epocal. A primeira refere-se a momentos históricos mais gerais: na época das grandes navegações, Timor se tornou colônia portuguesa. Em seguida, num contexto de Guerra Fria, a Indonésia invade a RDTL com apoio do lado capitalista da guerra (E.U.A.). Por fim, após a restauração da independência, que é precedida pelo fim da Guerra Fria, Timor é inserido num contexto de capitalismo neoliberal. As subunidades aqui podem ser entendidas como questões locais que, apesar de suas diferenças, possuem um mesmo objetivo em sua totalidade (independência do país).

${ }^{10}$ Empresa portuguesa responsável pela exploração do café em Timor-Leste e pelo início do processo de concentração de terras nas mãos de estrangeiros.

11 A língua portuguesa no Timor está em formação e, portanto, possui características próprias. (RAMOS et. al., 2015)

${ }^{12}$ Tema Gerador surge como a própria compreensão coletiva do educando ligada a sua realidade, questionando-a como determinante do atual estágio do capitalismo. Para realização na prática, o Tema Gerador requer um processo de investigação, denominado como investigação temática. Nesse processo, ocorrem levantamentos de "sitaçõeslimites", a partir das contradições presentes nas falas, resultando num processo educativo que seja baseado em 


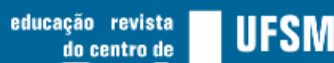 Ellibahao}

ISSN: 1984-6444 | http://dx.doi.org/10.5902/1984644434613

problemas reais que, atendam as reais necessidades dos educandos e da comunidade de forma geral. (FREIRE, 1997).

${ }^{13}$ Buscou-se nesse momento não tratar o termo rural, já que a concepção de rural e urbano difere da ocorrida no Brasil, por exemplo. Fica aberto aqui, um aprofundamento maior na temática em pesquisas posteriores sobre a relação entre urbano e rural.

14 "De acordo com Abílio Araújo, foi através do MRRP que os alunos da Casa dos Timores aprenderam sobre Amílcar Cabral do PAIGC e sobre os movimentos anti-coloniais na África.” (SILVA, 2011, p. 60, tradução do autor)

${ }^{15}$ Por não constar essas informações no material pesquisado, cabe mais um questionamento: como se deu a difusão da propaganda política com o povo?

16 "Os escritos de Cabral são importantes porque os movimentos de libertação nacional teorizaram o papel de suas lutas num período prévio as formações realizadas pela FRETILIN." (SILVA, 2011, p. 79, tradução do autor)

${ }^{17}$ Segundo o pelo pensamento abissal, denomina-se pensamento pós-abissal como aquilo que não é conhecimento válido.

${ }^{18}$ Analfabeto. 